\title{
Speed Control of BLDC Using NARMA-L2 Controller in Single Link Manipulator
}

\author{
R. CELIKEL
}

\begin{abstract}
The BLDC motors are widely used in industrial applications. The load characteristic and controller are important to obtain optimum performance in the speed control of the BLDC motor because some problems are occurred in speed control of nonlinear loads which is used the conventional control methods. The single link manipulator used in robotic applications is a nonlinear system for control algorithms. The load of motor is determined on considering the conversion ratio of the reducer box. In this study, a single link manipulator system consist of BLDC motor, reducer gearbox and robot arm is controlled by using NARMA-L2 controller as known modern control method in used the control of the nonlinear systems. The NARMA-L2 controller is based on neural network. The single link manipulator system is analyzed by using MATLAB/Simulink environment. The speed control of the BLDC motor is performed in conditions the constant and nonlinear load. The results show that the speed control of BLDC motor is performed the high performance in nonlinear loads.
\end{abstract}

Index Terms-BLDC motor, Neural networks, NARMA-L2 controller, Single link manipulator.

\section{INTRODUCTION}

$\mathrm{T}$ HE BRUSHLESS direct current (BLDC) motors are widely used in industrial applications such as automotive technology, appliances, medical, industrial automation equipment, and aerospace application. The BLDC motors are used owing to their low weight, high power density, high efficiency, and high reliability [1].

The some problems such as steady state error, high overshoot and control response error are occurs in the speed control of the nonlinear loads. Nowadays, there are many industrial systems with non-linear parameters such as single link manipulator which is most basic part in robotic systems. It is difficult to achieve a nonlinear manipulator load using conventional control methods with high-speed tracking. The conventional control methods have been applied to various types of manipulators in the literature [2]. The nonlinear parameters of the single link manipulator load can be explicitly defined. These parameters are the gravitational

R. CELIKEL, is with Department of Electrical Engineering University of Batman University, Batman, Turkey, (e-mail: resat.celikel@batman.edu.tr).

(iD) https://orcid.org/0000-0002-9169-6466

Manuscript received January 8, 2019 accepted March 18, 2019. DOI: $\underline{10.17694 / \text { bajece. } 510170}$ force, the mass of the load, the position of the manipulator and the viscous friction. The modern control method is used to the control of nonlinear systems. The real-time applications using Nonlinear Autoregressive Moving Average (NARMA-L2) control method has been performed for a single link manipulator [3-4].

An adaptive control method has been developed for the small signal inputs that NARMA is unsuccessful and situations where NARMA model is unknown [5]. The NARMA-L2 controller has been used to control of the induction motors. The three-phase induction motor has been controlled by using PID, fuzz logic and NARMA-L2 control methods and the obtained results have been compared [5-8]. The simulation of the induction motors' control has been performed by using PI, NARMA-L2 and fuzzy logic and more high performance has been obtained by using NARMA-L2 controller method than others control methods [9].

At the same time, NARMA-L2 controller has been used to control the speed of the different motor types. The speed control of DC motor has been performed using PID and the NARMA-L2 controllers and the results obtained have been compared among themselves [10]. The NARMA-L2 controller has been used to many applications apart from motor control applications. NARMA-L2 controller and PID controller have been used for control of the scaled-model helicopters. The superiority performance of the NARMA-L2 controller is demonstrated by the simulation [11].

In another study, a pendulum has been connected to the flywheel and a gyroscope inverter pendulum (GIP) has been performed. The real-time application of the GIP control has been achieved using NARMA-L2 controller [12]. A novel adaptive NARMA-L2 controller has been implemented to control of the nonlinear systems and the novel controller has been based on support vector regression (SVR). Against the measurement noises and uncertainty of the system parameters have been analyzed the controller durability. As a result of, the proposed control method is quite successful in suppressing measurement noise and uncertainty of the system parameters [13]. The synergy control has been proposed for a robot arm to follow a certain orbit. This control consists of a combination of the NARMA-L2 and the PD controller and has been obtained a very high performance [14].

The control of unmanned aerial vehicles is quite difficult due to the dynamic of the vehicle has a non-linear structure. The NARMA-L2 controller has been used to control the unmanned aircraft and the controller successful has been shown in simulation results [15]. A simulation has been performed to analyze instant changes of the two-area power system, which has been controlled by using PID, fuzzy logic 
and NARMA-L2 controller. The controller performance has been compared in different situation [16].

A new MIMO ANFIS-based NARMA-L2 controller has been proposed and compared with other PI, PID, Fuzzy, GA and PSO controlled Fuzzy logic controls. The superiority of the proposed method in low tracking error and time response behaviors has been demonstrated by the simulation [17].

The NARMA-L2 controller has been implemented to obtain the optimum performance from maximum power point tracking algorithm which is used in photovoltaic water pump system. The performance of the PID and NARMA-L2 controller has been compared and superiority performance of the NARMA-L2 controller has been shown in simulation environment [18]. GA-adjusted Fuzzy system controller and NARMA-L2 controller have been implemented by using a simulation study for 5-degree of freedom robotic system. The simulation of the system has been performed in MATLAB/Simulink environment and obtained results have been compared [19].

In this study, the speed control of the BLDC motor is performed by using NARMA-L2 controller in MATLAB/Simulink environment at conditions constant load and nonlinear load. A single link manipulator is used as the nonlinear load. This manipulator is driven by a dc gear-motor. The nonlinear load and inertia of the manipulator is degraded to the motor side. Thus, the angular position control of the motor is obtained similar to the real system. The results are analyzed by using MATLAB / Simulink environment.

\section{Modelling OF Single LiNK MANIPULATOR}

The control of electric motors is quite difficult in nonlinear loads. The conventional control methods are caused some problems in nonlinear loads such as steady state error and failure to adapt at unexpected situations. Nowadays, the nonlinear control methods are preferred to obtain high performance in control of the nonlinear loads. A single-link manipulator is widely used as the basis for studies in the robotic system control. The single link manipulator is nonlinear loads for the BLDC motor. In this study, a single link manipulator is used to control the speed of the BLDC motor.

Today BLDC motors are preferred as actuators, especially for the movement of industrial robot arms. The most important reason of this motor are preferred; high efficiency, high power/volume density, stable operation, lack of brushes and physical commutator and good dynamic response. The speed of the BLDC motors used in robotic applications can sometimes up to $20.000 \mathrm{rpm}$. The output speed of the gearbox is reduced and its torque is increased by using a step-down gearbox between the robot arm and the motor, assuming that the output power of the gearbox is equal to the output power of the motor. The single link manipulator is shown in Fig. 1.

The drive of BLDC motors are preferred six-step switching due to simple structure. In this technique, two phase windings are in connection at any time. It can be expressed by the equations of the conventional DC motor when a BLDC motor is controlled by a six-step switching technique. The voltage and torque of motor are obtained as shown Eq. (1) and Eq. (2), respectively.

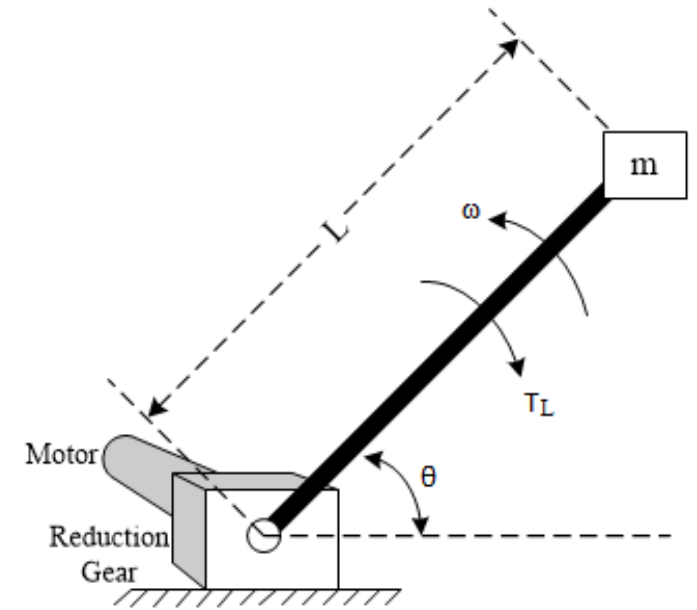

Fig.1. Single-link manipulator

$$
\begin{gathered}
V=i_{s} R_{s}+L_{s} \frac{d i_{s}}{d t}+E_{z}, E_{z}=K_{e} \omega_{m} \\
T_{m}=T_{L}+J_{m} \frac{d \omega_{m}}{d t}+B_{m} \omega_{m}, T_{m}=K_{t} i_{s}
\end{gathered}
$$

where $V$ is the motor voltage, $i_{s}$ is the motor current, $R_{s}$ is motor winding resistance, $L_{s}$ is winding inductance of the motor, $K_{e}$ is speed constant, $\omega_{m}$ is motor angular velocity, $T_{m}$ is the developed torque by the motor, $T_{L}$ is load torque, $J_{m}$ is inertia of the motor, $B_{m}$ is friction coefficient of the motor, $K_{t}$ is torque constant of the motor.

The load torque applied to motor is given in Eq. (3). The ratio of the gearbox connected to single link manipulator is taken into account when the load torque is calculated. The conversion ratio of the gearbox is given as shown in Eq. (4). The motor speed can be derived from the positon of the motor as shown in Eq. 5. The load torque of the single-link manipulator and the developed torque from the motor shaft are given in Eq. (6) and Eq. (7), respectively.

$$
\begin{gathered}
T_{L}=\left(\frac{1}{u}\right)^{2}\left(\frac{1}{2} m L^{2}\right) \frac{d^{2} \theta}{d t^{2}}+\left(\frac{1}{u}\right)^{2} B L \frac{d \theta}{d t}+\left(\frac{1}{u}\right) m g L \cos \theta \\
u=\frac{\omega_{m}}{\omega_{L}} \\
\omega_{m}=\frac{d \theta}{d t} \\
T_{m}=\left(\frac{1}{u}\right)^{2}\left(\frac{1}{2} m L^{2}\right) \frac{d \omega_{m}}{d t}+\left(\frac{1}{u}\right)^{2} B_{L} \omega_{m} \\
+\left(\frac{1}{u}\right) m g L \cos \theta+J_{m} \frac{d \omega_{m}}{d t}+B_{m} \omega_{m}
\end{gathered}
$$




$$
\begin{aligned}
& T_{m}=\left[\left(\frac{1}{u}\right)^{2}\left(\frac{1}{2} m L^{2}\right)+J_{m}\right] \frac{d \omega_{m}}{d t} \\
& +\left[\left(\frac{1}{u}\right)^{2} B_{L}+B_{m}\right] \omega_{m}+\left(\frac{1}{u}\right) m g L \cos \theta
\end{aligned}
$$

where $\omega_{L}$ is angular velocity of the load, $B_{L}$ is the friction coefficient of the load, $u$ is the ratio of the gearbox, $m$ is the mass of the load, $L$ is the arm length, $g$ is the force of gravity.

\section{DESIGN OF NARMA-L2 CONTROLLER}

Artificial Neural Network (ANN) based control methods are popular due to their skills, learning, and approach in control of nonlinear systems. These control methods are frequently used in the control and identification of dynamic systems in recent years. One of the most suitable methods is NARMA-L2 controller for controlling time-dependent and nonlinear systems. NARMA-L2 controller consists of two steps such as determination of the system to be controlled and design of system control.

The behavior of the nonlinear discrete time system is examined in the system determination step is shown in Eq. 8.

$$
\begin{aligned}
& y(k+d)=N(y(k), y(k-1), \ldots, y(k-n+1), \\
& u(k), u(k-1), \ldots, u(k-m+1))
\end{aligned}
$$

where $\mathrm{u}(\mathrm{k})$ and $\mathrm{y}(\mathrm{k})$ are system input and system output, respectively. $m$ and $n$ are the measured delay values of the inputs and outputs, respectively. $\mathrm{d}$ is relative degrees. Multilayer neural networks can be used to define $\mathrm{N}$ nonlinear function.

If the system follows a reference, the nonlinear controller can be shown as Eq. 9. Neural network training can be used to determine the $\mathrm{G}$ function that minimizes the mean square error using the back-propagation algorithm. In this case, the NARMA-L2 controller can be obtained as in Eq. 10.

$$
\begin{gathered}
u(k)=G(y(k), y(k-1), \ldots, y(k-n+1), \\
\left.y_{r}(k+d), u(k-1), \ldots, u(k-m+1)\right) \\
\hat{y}(k+d)=f[y(k), y(k-1), \ldots, y(k-n+1), \\
u(k-1), \ldots, u(k-m+1)]+g[y(k), y(k-1), \ldots, y(k-n+1), \\
u(k-1), \ldots, u(k-m+1)] . u(k)
\end{gathered}
$$

The advantage of this form of reference system outputs can be solved for the control input that causes the tracking. The obtained controller is shown in Eq. 11.

$$
u(k)=\frac{y_{r}(k+d)-f[y(k), y(k-1), \ldots, y(k-n+1), u(k-1), \ldots, u(k-n+1)]}{g[y(k), y(k-1), \ldots, y(k-n+1), u(k-1), \ldots, u(k-n+1)]}
$$

However, it is not practical to define the input that depends on the output. For this reason, Eq. 12 is used for system definition for $\mathrm{d} \geq 2$.

$$
\begin{aligned}
& y(k+d)=f[y(k), y(k-1), \ldots, y(k-n+1), \\
& u(k), u(k-1), \ldots, u(k-n+1)]+g[y(k), y(k-1), \ldots, y(k-n+1), u(k), \\
& u(k-1), \ldots, u(k-n+1)] . u(k+1)
\end{aligned}
$$

The NARMA-L2 controller is obtained as shown in Eq. 13.

$$
u(k+1)=\frac{y_{r}(k+d)-f[y(k), \ldots, y(k-n+1), u(k), \ldots, u(k-n+1)]}{g[y(k), \ldots, y(k-n+1), u(k), \ldots, u(k-n+1)]}
$$

The general form of the NARMA-L2 controller is illustrated in Fig. 2 as the simplest structure. The hidden layer also has only one neuron. However, more neurons are needed in practice. At the same time, the number of delayed inputs is also important because the degree of the system model is unknown. The NARMA-L2 controller must be connected to the system as shown in Fig. 3 after the training process is completed. The DC motor and the system parameters used in this study are given in Table I.

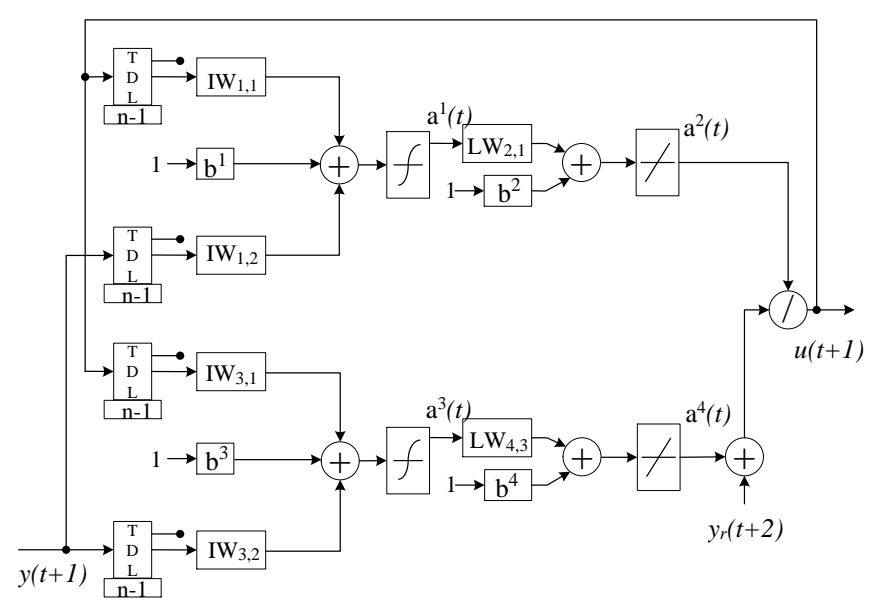

Fig.2. The simplest form of NARMA-L2 controller

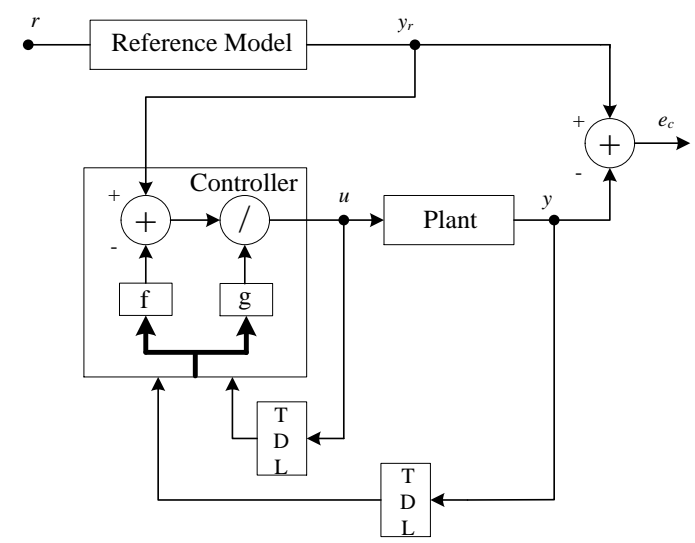

Fig.3. The block diagram of NARMA-L2 controller connected the system 
BALKAN JOURNAL OF ELECTRICAL \& COMPUTER ENGINEERING, Vol. 7, No. 2, April 2019

TABLE I

THE PARAMETERS OF THE DC MOTOR AND THE SYSTEM

\begin{tabular}{|l|l|l|l|}
\hline Symbol & Unit & Parameter & Value \\
\hline$V$ & $\mathrm{~V}$ & Nominal voltage & 48 \\
\hline$R$ & $\Omega$ & Terminal resistance & 1.03 \\
\hline$L$ & $\mathrm{mH}$ & Terminal inductance & 0.204 \\
\hline$i_{s}$ & $\mathrm{~A}$ & Nominal current & 4.06 \\
\hline$K_{t}$ & $\mathrm{mNm} / \mathrm{A}$ & Torque constant & 44.8 \\
\hline$K_{e}$ & $\mathrm{rpm} / \mathrm{V}$ & Speed constant & 213 \\
\hline$\omega_{m}$ & $\mathrm{rpm}$ & Nominal speed & 9250 \\
\hline$T_{m}$ & $\mathrm{mNm}$ & Nominal torque & 170 \\
\hline$J_{m}$ & $\mathrm{kgm}{ }^{2}$ & Torque of the total inertia & 0.0000101 \\
\hline$B_{m}$ & $\mathrm{Nms} / \mathrm{rad}$ & $\begin{array}{l}\text { Friction constant of the } \\
\text { motor }\end{array}$ & $\sim 0$ \\
\hline$B_{L}$ & $\mathrm{Nms} / \mathrm{rad}$ & $\begin{array}{l}\text { Friction constant of the } \\
\text { payload }\end{array}$ & 0.0001 \\
\hline$m$ & $\mathrm{~kg}$ & Mass of the payload & 1 \\
\hline$g$ & $\mathrm{~m} / \mathrm{s}^{2}$ & Gravitational force & 10 \\
\hline$L$ & $\mathrm{~m}$ & $\begin{array}{l}\text { Length of manipulator } \\
\text { arm }\end{array}$ & 1 \\
\hline$u$ & $\begin{array}{l}\text { Conversion ratio of } \\
\text { reduction gear }\end{array}$ & 100 \\
\hline
\end{tabular}

\section{Simulation Results}

The simulation is performed by using MATLAB/Simulink environment. In this study, the size of hidden layers is determined as 20 , the number of delay inputs is taken as 3 and the number of delay outputs is taken as 2 . These data are usually obtained by performing simulation study. The sample time of the network is $0.001 \mathrm{~s}$ and the number of data input and output trained by neural network is 10000 in this time. The results of the system identification and neural network training in MATLAB/Simulink environment are shown in Fig.4. The system input and output, NN output and the error between system output and NN output are given in Fig. 5.

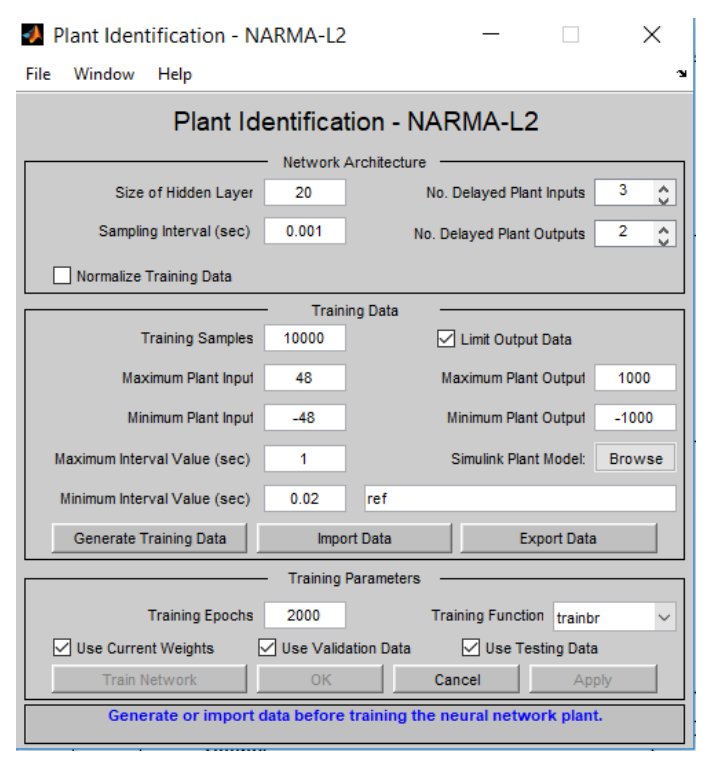

Fig.4. The plant identification of the NARMA-L2 and NN training in MATLAB/Simulink environment
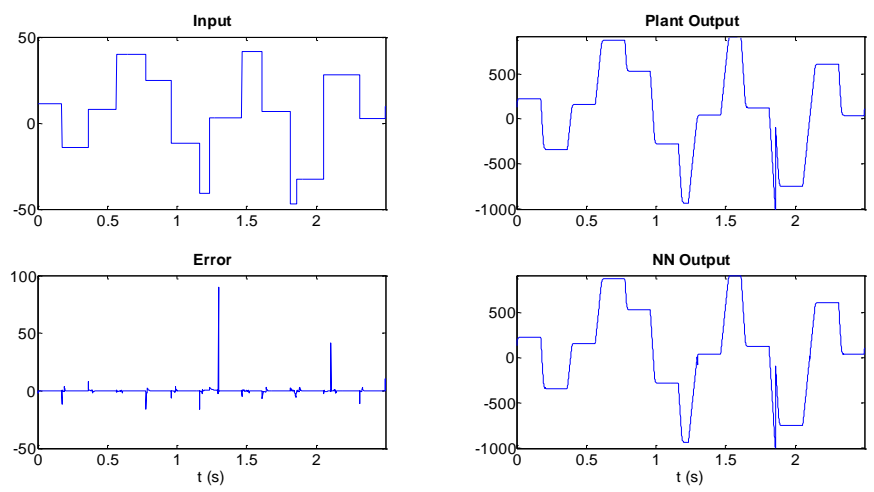

Fig.5. The system input, the plant output, the NN output and error between plant output and $\mathrm{NN}$ output after the NN training

A speed control simulation of a DC motor, gear and singlelink manipulator reduced by dc motor in MATLAB/Simulink environment is performed as illustrated in Fig.6. At the same time, the simulation is performed to control the speed of dc motor under constant load by using NARMA-L2 controller.

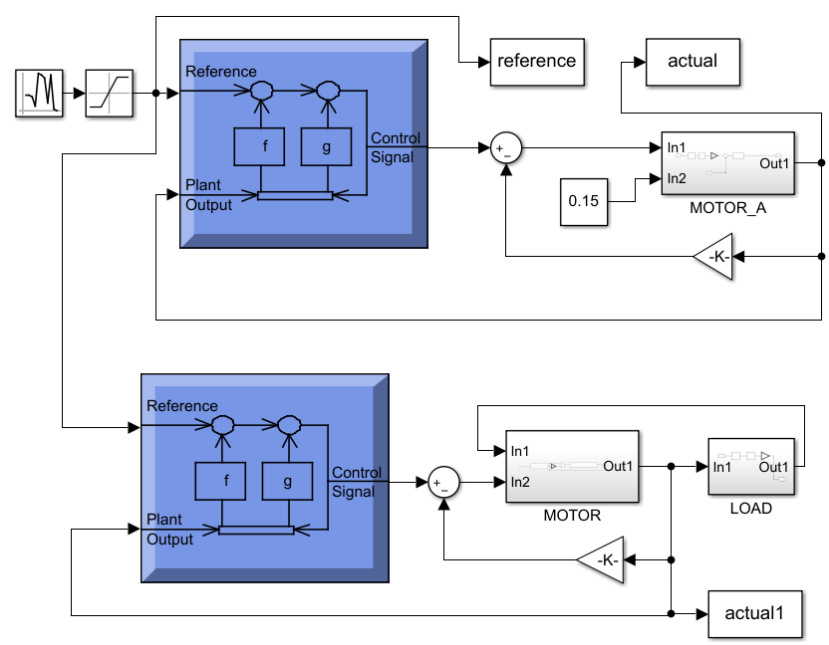

Fig.6. The control of motor by using NARMA-L2 in condition single-link manipulator load and constant load.

The desired speed of the motor is applied in the reference input in radians as shown in Fig. 7. The speed of the manipulator connected to the output of the gear is as low as the conversion ratio. The torque of the single-link manipulator is applied to the motor as a load. The gearbox conversion ratio is included in the system when the motor load torque is calculated.

Fig. 7 shows the results of the simulation. The simulation results showed that the motor speed is tracked to the various reference inputs as desired.

In Fig.7, the load applied the motor is given as $0.15 \mathrm{Nm}$. The motor speed is track the reference speed with a low error. The overshoot is almost zero in transient response. In addition to, the speed of motor is catch the reference speed without oscillation. The motor speed of the single link manipulator is shown in Fig. 8. 


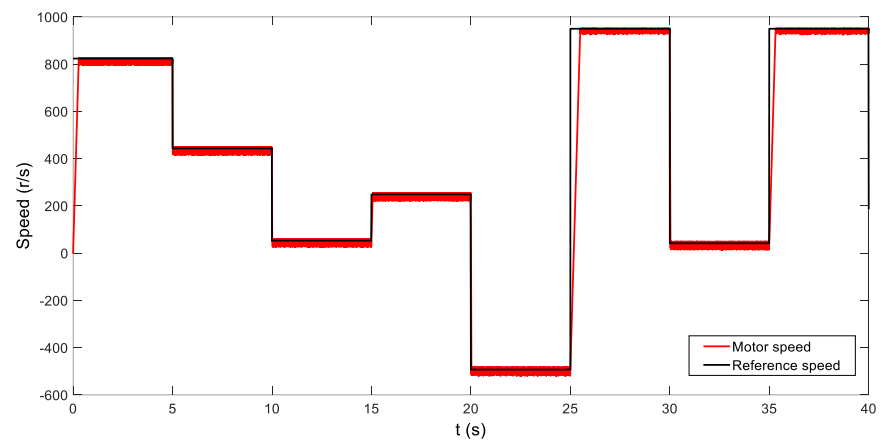

Fig.7. The motor speed under constant load.

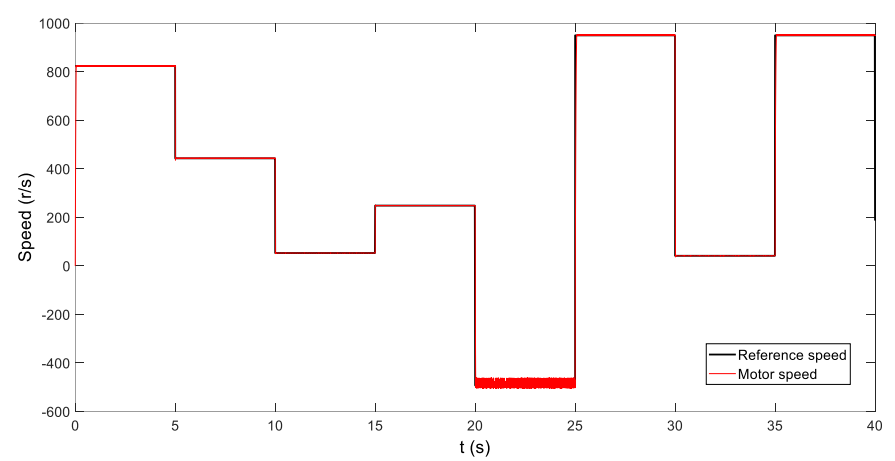

Fig.8. The motor speed under single link manipulator load.

The gearbox conversion ratio and other system parameters is consider while the torque applied to the motor is calculate. The simulation of motor load is performed by using Table 1 . The speed of the motor tracks the reference speed approximately zero overshoot and very quickly, as seen in Figure 8. This demonstrates the success of the NARMA-L2 controller in controlling the nonlinear systems. Fig. 9 shows the motor speed reaching up to reference speed between $14.5^{\text {th }}$ and $15.5^{\text {th }}$ seconds.

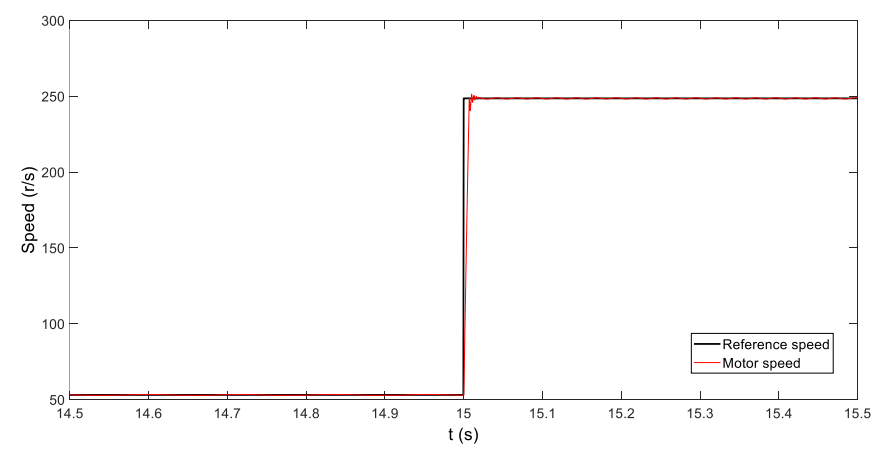

Fig.10. The result of simulation between $14.5^{\text {th }}$ and $15.5^{\text {th }}$ seconds.

\section{CONCLUSION}

The single link manipulator is nonlinear system due to nonlinear loads. The control of the nonlinear loads is performed by using nonlinear control methods because the conventional control methods is insufficient in the control of this loads. NARMA-L2 controller is the nonlinear control method which is used neural network. In this study, the speed of ta single link manipulator has been controlled by using NARMA-L2 controller. The controlled system consists of a dc motor, a reducer gearbox connected between the motor and a single-link manipulator. Different speed values are applied to the NARMA_L2 controller input as reference for 40 seconds. The simulation has been performed under condition both constant load and single link manipulator load. As a result of the simulation study, the speed of the motor is tracked by high accuracy with reference speed in both load condition. This study showed that the NARMA controller could be used in both constant loads and nonlinear loads such as single link manipulator.

\section{REFERENCES}

[1] R. Çelikel, M. Özdemir, and Ö. Aydoğmuş, "Implementation of a flywheel energy storage system for space applications," Turkish J. Electr. Eng. Comput. Sci., Vol.25, 2017, pp. 1197-1210.

[2] J.Y.S. Luh, "Conventional Controller Design for Industrial Robots-A Tutorial," IEEE Trans. Syst. Man Cybern., Vol.SMC-13, No. , 1983, pp.298-316.

[3] Wahyudi, S.S. Mokri, and A.A. Shafie, "Real time implementation of NARMA L2 feedback linearization and smoothed NARMA L2 controls of a single link manipulator,” Proc. Int. Conf. Comput. Commun. Eng. 2008, ICCCE08 Glob. Links Hum. Dev., pp.691-697, 2008.

[4] S.S. Mokri, H. Husain, W. Martono, A. Shafie, U.K.M. Bangi, and S. De, "Real Time Implementation of NARMA-L2 Control of a Single Link Manipulator Faculty of Engineering, Kulliyah of Engineering, International Islamic University of Malaysia , 50728 , Kuala Lumpur, Malaysia," Am. J. Appl., Vol.5, No.12, 2008, pp. 1642-1649.

[5] O. Adetona, S. Sathananthan, and L.H. Keel, "Robust adaptive control of nonaffine nonlinear plants with small input signal changes," IEEE Trans. Neural Networks, Vol.15, No.2, 2004, pp.408-416.

[6] M. George and K. Prasad Basu, "NARMA-L2 controlled variable frequency three-phase induction motor drive," Eur. J. Sci. Res., Vol.70, No.1, 2012, pp. 98-111.

[7] T.D. Dongale, T.G. Kulkarni, S.R. Ghatage, and R.R. Mudholkar, "Implementation and Comparative study of Three Phase Induction Motor Control Using PID Controller, Fuzzy Logic and Neural Network Techniques," International Journal of Science and Research, 2012, pp. 271-275.

[8] I. Iulia and A. Mihail, "Design of NARMA-L2 Neural controller for an Induction Motor' s Speed Control," Journal of Computer Science \& Control Systems, Vol.6, No.2, 2013, pp. 18-22.

[9] H. Abu-Rub and A. Awwad, "Artificial neural networks and fuzzy logic based control of AC motors," Int. Electr. Mach. Drives Conf. (IEMDC 2009), No.1, 2009., pp. 1575-1580.

[10] M. Alhanjouri, "Speed control of DC motor using artificial neural network," International Journal of Science and Research, Vol.6, No.2, 2012, pp. 2104-2148.

[11] M.R. Khaldi, A. El, and H. Hassan, "State estimation based optimal control and NARMA-L2 controllers of a scaled-model helicopter," IFAC, 2009, Vol.2, No. PART 1.

[12] F. Chetouane and S. Darenfed, "Neural network NARMA control of a gyroscopic inverted pendulum,” Eng. Lett., Vol.16, August, 2008, pp.16.

[13] K. Uçak and G. Öke Günel, "A novel adaptive NARMA-L2 controller based on online support vector regression for nonlinear systems," Neural Process. Lett., Vol.44, No.3, 2016, pp. 857-886.

[14] J. Kananai, "Stiff PD and Narma L2 synergy control for a nonlinear mechanical system," Eur. J. Sci. Res., Vol.77, No.3, 2012, pp. 350-361.

[15] Y. Jiang, D. Necsulescu, and J. Sasiadek, "Robotic unmanned aerial vehicle trajectory tracking control," IFAC, 2006, Vol.39, No.15.

[16] S.A. Azeer, R. Ramjug-Ballgobin, and S.Z. Sayed Hassen, "Intelligent controllers for load frequency control of two-area power system," IFACPapers On Line, 2017, Vol.50, No.2, pp.301-306.

[17] Y. Al-Dunainawi, M.F. Abbod, and A. Jizany, "A new MIMO ANFISPSO based NARMA-L2 controller for nonlinear dynamic systems," Eng. Appl. Artif. Intell., Vol.62, November, 2016, pp. 265-275.

[18] A.M. Kassem, "MPPT control design and performance improvements of a PV generator powered DC motor-pump system based on artificial neural networks," Int. J. Electr. Power Energy Syst., Vol.43, No.1, 2012, pp. $90-98$. 
[19] V. Bhatia, V. Kalaichelvi, and R. Karthikeyan, "Comparison of GA tuned fuzzy logic and NARMA-L2 controllers for motion control in 5DOF robot," Int. J. Comput. Appl., Vol.39, No.2, Apr. 2017, pp. 69-78.

\section{BIOGRAPHY}

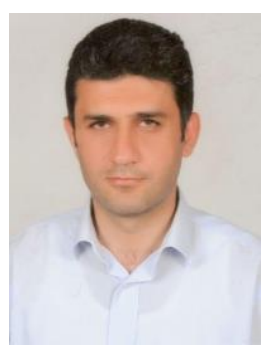

RESAT CELIKEL was born in 1980. He received B.S, M.S and $\mathrm{PhD}$ degrees from

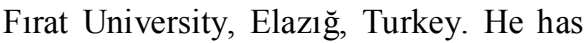
been working as an Assist. Prof. Dr. at Batman University. His current interests are BLDC motors, flywheel energy storage, FPGA, motor drive. 